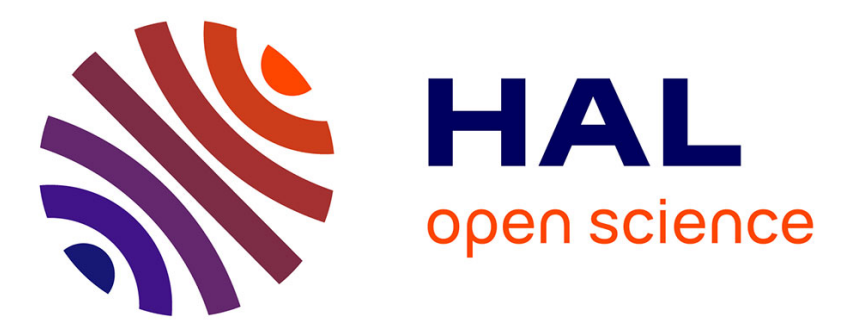

\title{
Design of a New Broadband Dielectric Resonator Antenna
}

\author{
Yacouba Coulibaly, Tayeb Denidni, Halim Boutayeb, Larbi Talbi
}

\section{To cite this version:}

Yacouba Coulibaly, Tayeb Denidni, Halim Boutayeb, Larbi Talbi. Design of a New Broadband Dielectric Resonator Antenna. The European Conference on Antennas and Propagation: EuCAP 2006, 2006, Nice, France. p.442.1. hal-00166633

\section{HAL Id: hal-00166633 https://hal.science/hal-00166633}

Submitted on 8 Aug 2007

HAL is a multi-disciplinary open access archive for the deposit and dissemination of scientific research documents, whether they are published or not. The documents may come from teaching and research institutions in France or abroad, or from public or private research centers.
L'archive ouverte pluridisciplinaire HAL, est destinée au dépôt et à la diffusion de documents scientifiques de niveau recherche, publiés ou non, émanant des établissements d'enseignement et de recherche français ou étrangers, des laboratoires publics ou privés. 


\title{
DESIGN OF A NEW BROADBAND DIELECTRIC RESONATOR ANTENNA
}

\author{
Yacouba Coulibaly ${ }^{(1)}$, Tayeb A. Denidni ${ }^{(1)}$, Halim Boutayeb ${ }^{(1)}$ Larbi Talbi $^{(2)}$ \\ (1) INRS Énergie Matériaux et télécommunications, 800, rue de La Gauchetière Ouest, Bureau 6900 \\ Montréal, Québec, Canada H5A 1K6,Email: couli@emt.inrs.ca

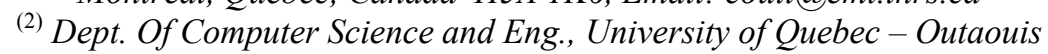 \\ Hull, Quebec, Canada, J8X3X7
}

\begin{abstract}
In this paper, a new microstrip broadband antenna is proposed. This antenna was numerically designed using Ansoft HFSS simulation software package. The investigated antenna uses a dielectric resonator, a microstrip fed stepped patch, and an intermediate substrate to widen the bandwidth. A parametric study was performed to optimize the proposed design. Then, based on the optimised design, an antenna prototype was fabricated and measured. Simulations and measurements were carried out, and the comparison between them shows a good agreement. Using this approach, a fractional bandwidth of $42 \%$ at the center frequency of $9.64 \mathrm{GHz}$ was achieved.
\end{abstract}

\section{INTRODUCTION}

Over the last years, there has been a substantial growth of multi-band and broadband applications, which leads designers to develop new antennas configuration. Dielectric Resonator Antennas (DRAs) have shown to be an attractive alternative for applications at microwave and millimeter wave-bands. DRAs have some key features for the design of planar antennas: low loss, low profile, high radiation efficiency, high density integration, and reduced size.

However, the bandwidth of a DRA is generally below $10 \%$ [1] and this narrow bandwidth is not enough for modern applications. Therefore, different approaches have been proposed to increase the bandwidth. In respect to this issue, different shapes of DRAs such as, conical [2], tetrahedron and triangular [3] have been proposed. Another method for bandwidth enhancement is based on stacking two or more elements of different sizes with the same or different dielectric material to improve the coupling between the feedline and the antenna [4]. Coplanar parasitic DRAs can also be used to increase the bandwidth [5]. These methods are little difficult to be fabricated. For this, a new alternative approach based on a hybrid structure has been proposed recently [6-8]. This method uses the combination of different types of resonant of different structures to design a wideband hybrid structure. Furthermore, a low profile DRA fed by a microstrip has been investigated in [9]. This antenna uses a stepped microstrip to achieve an efficient coupling, and a bandwidth of $17 \%$ has been obtained.

In this paper, a new DRA is proposed. This antenna uses three parts: a dielectric resonator (DR), an intermediate substrate and a microstrip fed stepped patch. Based on the simulation results, a prototype of the antenna was fabricated and measured. The simulation results including the return loss, the radiation pattern as well as the measured return loss are presented. In Section 2, the antenna design is described, and in Section 3, the simulated and measured results are compared and discussed. Finally, conclusions are made in Section 4.

\section{ANTENNA DESIGN}

The topology of the proposed hybrid antenna is shown in Fig 1. The antenna consists of a Dielectric Resonator (DR), an intermediate substrate and a microstrip fed patch. The DR has a height $2 d$, width $b$, length $a$, and relative permittivity $\varepsilon_{d r a}$. The intermediate substrate of thickness $h_{2}$ and permittivity $\varepsilon_{2}$ is inserted between the dielectric resonator and the microstrip feed as shown in Fig.1. The intermediate substrate is a square of width $W_{i .}$. The feeding circuit is composed of a microstrip feed line of width $W$ connected to a stepped patch as illustrated in Fig 1.b. The patch consists of three strips and their geometric dimensions are shown in Fig.1. The distance from the edge of the DRA to the edge of the patch is $d$.

To simulate this design, HFSS was used [10].. This antenna has the advantages of having different parameters which can be adjust to have a good impedance matching. Several prototypes are simulated to investigate the effects of some parameters.

In this design, the fundamental mode of the DRA $T E_{111}^{y}$ which is a hybrid mode is excited. For the DRA, the resonant frequency, the permittivity, the width, the length and the height are $11 \mathrm{GHz}, 10.2,10.4 \mathrm{~mm}, 10.4$ $\mathrm{mm}$ and $2.54 \mathrm{~mm}$, respectively. Fig. 2 shows the return loss coefficients for various thickness of the in intermediate substrate while the others design parameters are held constant. The intermediate substrate is used to lower the permittivity of the DR; therefore the bandwidth can be increased. From the parametric study shown in Fig.2, it can be concluded that the optimized value of $h_{2}=0.8 \mathrm{~mm}$. Referring to 
Fig.2, the return loss indicates that when $h_{2}$ increases, the DRA resonance frequency shifts down.
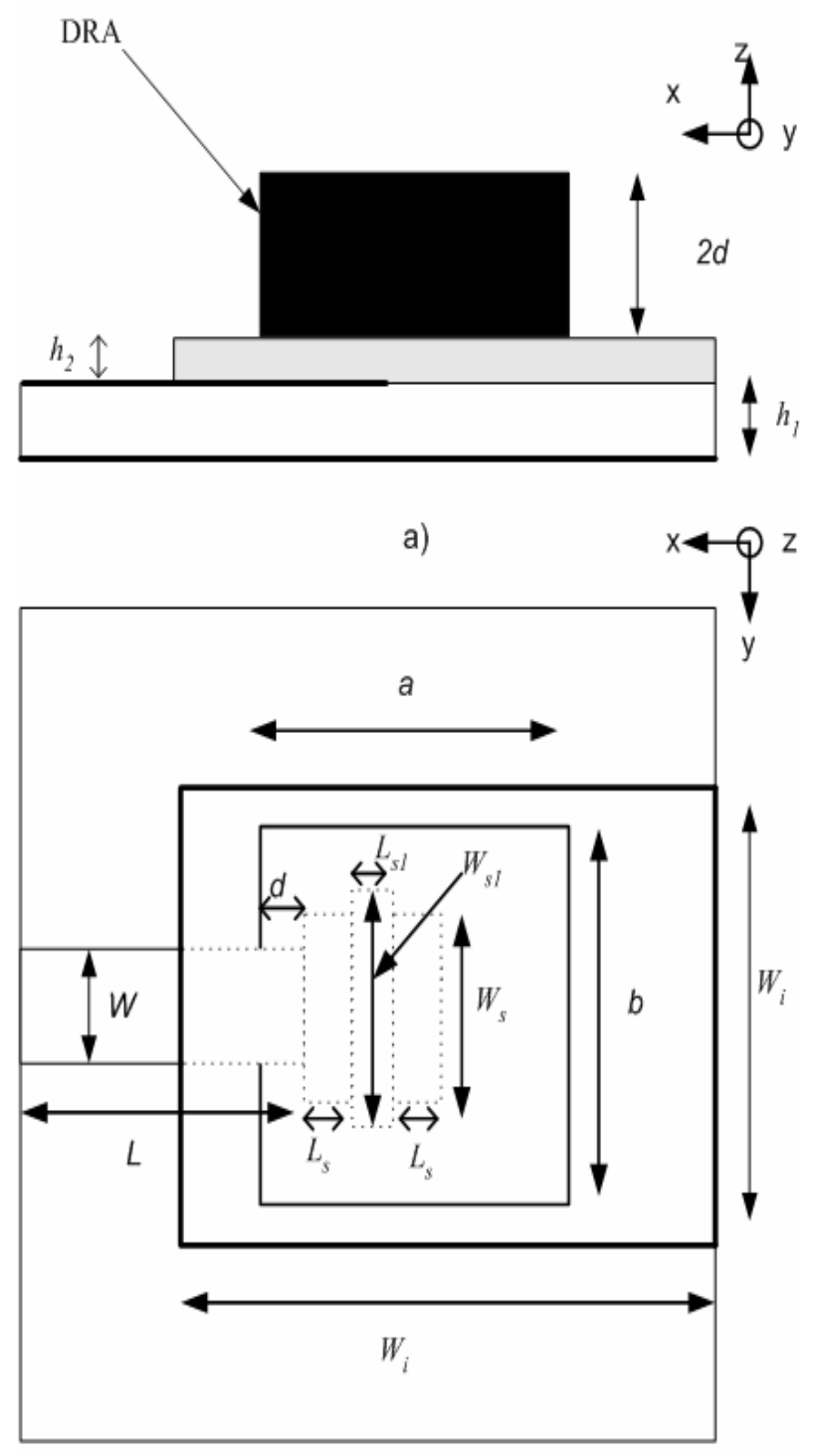

b)

Figure 1. Geometric configuration of the proposed antenna. a) Side view; b) top view.

The next parameter to be analyzed is the distance between the edge of the DRA and the edge of the patch. Fig. 3 shows that the choice of $d$ affects the bandwidth of the DRA. The choice of this parameter is critical to have an efficient coupling

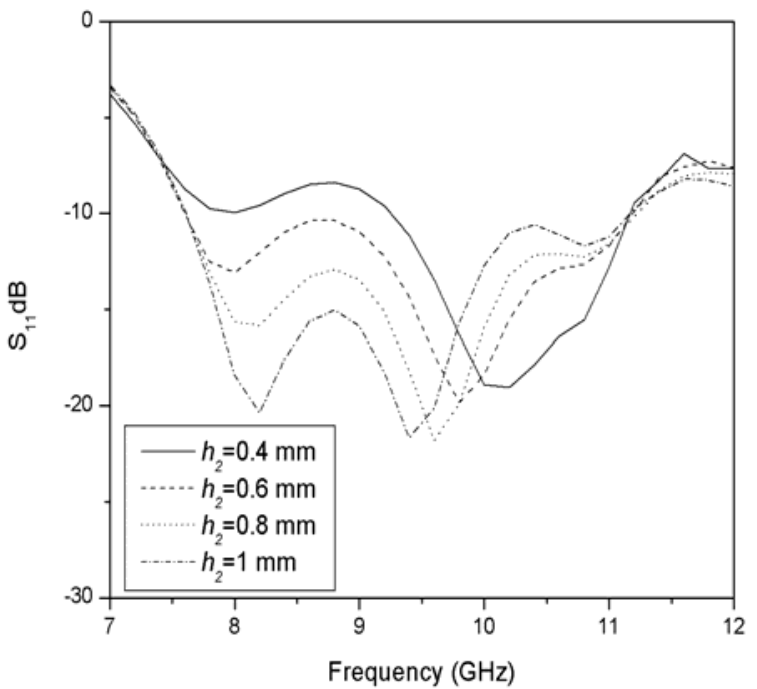

Figure 2. Return loss for different values of $h_{2}$.

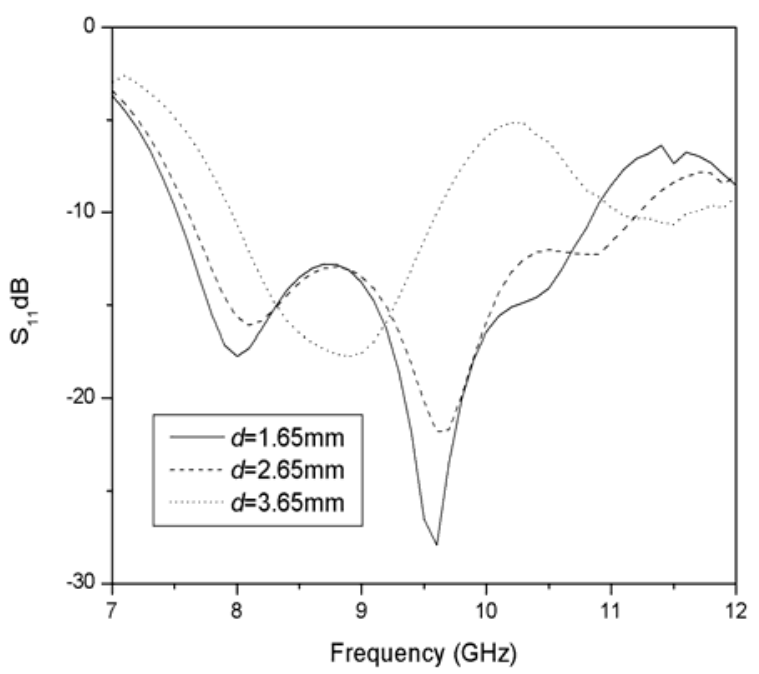

Figure 3. Return loss for different values of $d$.

\section{EXPERIMENTAL RESULTS}

To validate the proposed design, an antenna prototype was fabricated based on the optimized values. In order to make measurements of the $\mathrm{S}$ parameters, a coaxial connector is soldered to the microstrip line of the antenna. The DRA is made of a RT/Duroid 6010 of permittivity $\varepsilon_{d r a}=10.2$. A standard substrate of thickness of $2.54 \mathrm{~mm}$ of is used. The microstrip line and the patch are printed on the same substrate but with a standard thickness $h_{l}=1.27 \mathrm{~mm}$. The intermediate circuit is fabricated out of a substrate RT/Duroid 3060 of permittivity $\varepsilon_{l}=2.2$ and thickness $h_{2}=0.8 \mathrm{~mm}$. Using a 
network analyzer, experimental measurements on the fabricated prototype were carried out. The measured and simulated S parameters are shown in Fig. 4. From these curves, it can be observed that there is a good agreement between the measured and simulated results. However, there is a shift between the measured and simulated frequencies. The corresponding bandwidth of $40 \%$ and $42 \%$ (for return loss $<-10 \mathrm{~dB}$ ) at the center frequency of $9.35 \mathrm{GHz}$ and $9.64 \mathrm{GHz}$ is achieved for the simulation and the experimental results.

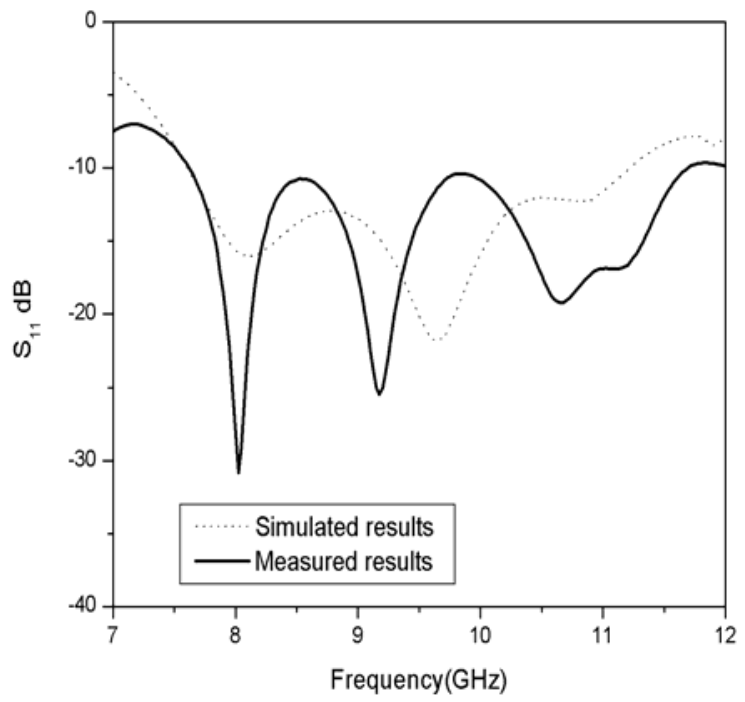

Figure 4 Simulated and measured return loss of the proposed antenna. The dimensions of he antenna: $a=$ $b=10.4 \mathrm{~mm}, 2 \mathrm{~d}=2.54 \mathrm{~mm}, \varepsilon_{1}=\varepsilon_{d r a}=10.2, \varepsilon_{2}=2.2$, $W_{=} 1.2 \mathrm{~mm}, L=27 \mathrm{~mm}, L_{s}=2 \mathrm{~mm}, W_{s}=5 \mathrm{~mm}, L_{s l}=1 \mathrm{~mm}$, $W_{s l}=7.5 \mathrm{~mm}, h_{2}=0.8 \mathrm{~mm}, W_{i}=30 \mathrm{~mm}$.

To examine the antenna radiation performance, experimental measurements were carried out in an anechoic chamber located at INRS-EMT, Montréal. The radiation patterns were measured at the frequencies of 8 , 9, and $10 \mathrm{GHz}$. The measured co-polarization in the Eand H-planes are shown in Figs. 5, 6 and 7. From these results, it appears that the patterns are stable across the operating bandwidth. The H-plane asymmetry is due to the radiation of the microstrip line and the patch. The ripples in the measured pattern are caused by the diffractions from the edge of the ground plane.

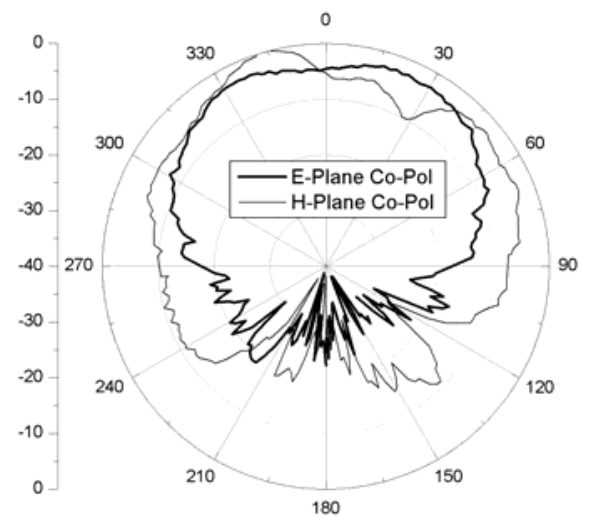

Figure 4. Measured radiation patterns at $8 \mathrm{GHz}$.

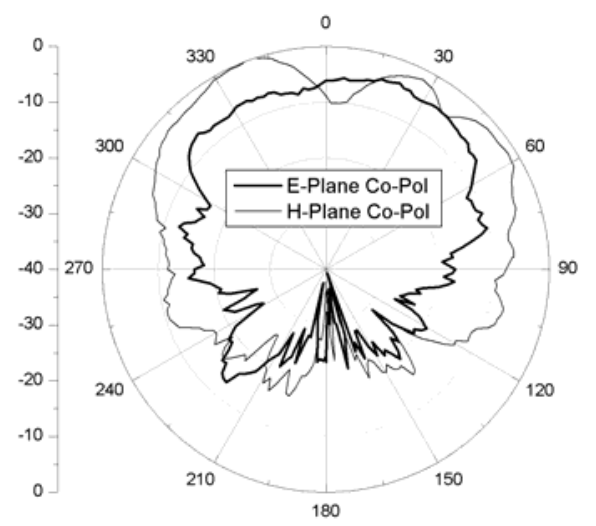

Figure 4. Measured radiation patterns at $9 \mathrm{GHz}$.

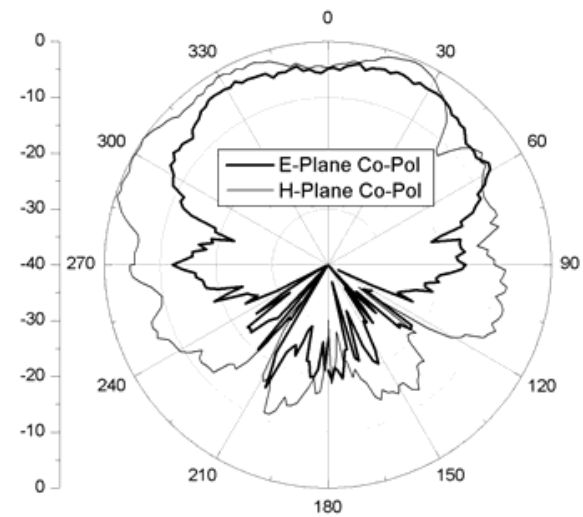

Figure 6. Measured radiation patterns at $10 \mathrm{GHz}$. 


\section{CONCLUSION}

In this paper, a design of a new low profile broadband dielectric resonator antenna has been investigated numerically and experimentally. The bandwidth is enhanced by adding an intermediate substrate and using a stepped patch for efficient coupling. A parametric investigation of different variables has been presented. A bandwidth of $42 \%$ with return loss less than $-10 \mathrm{~dB}$ at $9.64 \mathrm{GHz}$ is achieved and verified with experimental results. The radiation patterns of the proposed antenna have the same properties over the operating bandwidth. With the obtained features, this antenna can be suitable for broadband wireless communication systems at XBand.

\section{REFERENCE}

[1] K.M. Luk and K. W. Leung, Dielectric Resonator Antennas, Research Studies Press Ltd Press, Baldock, Herfordshire, UK, 2002 .

[2] A.A Kishk, B.Ahn and D. Kajfez," Broadband Stacked Dielectric Resonator" IEEE Electronic Letters, vol. 25, no18, pp 1232-1233, Aug 1999.

[3] A.A. Kishk , Y.Yin , W.Glisson , "Conical Dielectric Resonator Antennas For Wideband Applications" IEEE Trans. on Antennas and Propagations, vol. 50, no 4, pp 469-474, April 2002.

[4] A.A. Kishk, " Tetrahedron and Triangular Dielectric Resonator with wideband Performance " IEEE Antennas and Propagation Int. Symposium, vol.4, pp 462-465, June 2002.

[5] Z.Fan, Y.M.M Antar., A. Ittipiboon, and A. Petosa, "Parastic Coplanar Three-element Dielectric Resonator Antenna Subarray", Electronic Letters, vol. 32, no.9, pp 789-790 April 1996.

[6] A. Buerkle, K. Sarabandi and H. Mosallaei, "Compact slot and dielectric resonator antenna with dual-resonance, broadband characteristics" IEEE Trans. on Antennas and Propagations vol. 53, no.3, pp 1020-1027, March 2005.

[7] Q. Rao , T.A. Denidni, and A.R. Sebak, "A new dual-frequency hybrid resonator antenna", IEEE Antenna and Wireless propagation Lett., vol. 4, no.9, pp 308-311 April 2005.

[8] Q. Rao, T.A. Denidni, A.R. Sebak and R. H. Johnston.,"A dual band compact hybrid resonator antenna" Proc. IEEE Antennas and Propag. Symp. vol. 2A, pp 156-159, July 2005.

[9] M. Saed, and R. Yadla, "Microstrip-fed low profile and compact dielectric resonator antennas" PIER, no.56, pp 151-162, Jan. 2006.

[10] HFSS V.9, User's Guide, Ansoft Corporation, Pittsburgh, USA. 